\title{
ENSINANDO A SER PADRE NA DIOCESE DO PARÁ NOS OITOCENTOS
}

\author{
Allan Azevedo Andrade ${ }^{1}$ \\ Fernando Arthur de Freitas Neves ${ }^{2}$
}

\section{RESUMO}

Alinhado aos direcionamentos emanados de Roma, o bispo do Pará, D. José, se empenhou na reforma referente à formação clerical de sacerdotes na Amazônia. No entanto, não eram poucas as dificuldades de implantar o catolicismo diocesano na formação de padres já que, além da precariedade que vivia a diocese - por ter sido palco das turbulências resultantes do movimento cabano -, existiam também amarras por parte do Estado que limitavam a atuação do bispo ao tentar suprimir a modernidade emergente do século XIX. Mesmo assim, durante seu pastorado, D. José conseguiu contornar as adversidades imicuindo-se com o poder civil sobre a identidade católica tradicional, buscando a implantação e melhoramento dos estabelecimentos de ensino na diocese, a fim de solucionar o problema de clérigos incapacitados para a promoção do Ultramontanismo na Amazônia.

Palavras chave: Ultramontanismo; Seminário; Igreja; D. José.

\section{TEACHING TO BE PRIEST IN THE DIOCESE OF PARA IN EIGHT HUNDRED.}

\begin{abstract}
Aligned with the directions issued from Rome, the bishop of Pará, D. José, engaged in clerical reform on the formation of priests in the Amazon. However, there were few difficulties deploying the diocesan Catholic in the formation of priests since, in addition to precarious living the diocese - for having been the site of the resulting turmoil cabano movement - there were also bonds by the State which limited performance of the bishop to try to suppress the emerging modernity of the nineteenth century. Still, during his pastorate, D. José managed to overcome adversity up entangled with the civil power above its traditional Catholic identity, seeking the implementation and improvement of priestly education institutions in the diocese, in order to solve the problem of disabled clerics for promoting Ultramontanism in the Amazon.
\end{abstract}

Keywords: Ultramontanism; Seminar; Church; D. José.

\section{INTRODUÇÃO}

Temendo a crescente secularização da sociedade do século XIX a Igreja católica desejava restaurar sua condição de soberana do corpo e da alma da cristandade, por isso apresentou resistência contra os avanços do racionalismo moderno conforme intensificava o ensinamento de suas doutrinas, condenando os males que assombravam o exercício católico. As reverberações do Ultramontanismo alcaçaram a Amazônia em meados do século XIX através do bispo José Afonso de Moraes Torres, que, mesmo estando atrelado ao compromisso com o Estado, legitimidado pelo Padroado Régio, não descurou de aplicar os preceitos romanos na diocese do Pará. 
Todavia, para garantir a eficácia do projeto ultramontano, era essencial a criação de seminários, pois de lá despontariam sacerdotes moldados nas fornadas do catolicismo diocesano com o propósito de substanciar a presença cristã dentro de uma sociedade marcada pela escassez de práticas dos sacramentos exigidos por Roma. Por meio dos seminários episcopais, os bispos pretendiam educar religiosamente os jovens ansiando tranforma-los em padres alinhados ao Papa, tomando espaço dos clérigos desviantes dos padrões eclesiáticos rejeitados pela hierarquia católica ultramontana, para ocupar a posição de sacerdotes superiores, apolíticos e moralmente irrepreensíveis.

Destarte, o estudo em tela objetiva analisar a implatantação do Ultramontanismo na Amazônia por meio dos centros de formação sacerdotal, durante o bispado de D. José Afonso de Moraes Torres, que esteve à frente da diocese entre 1844 a 1857. Nesse âmbito, apesar de todas as dificuldades materiais e impedimentos que limitavam as ações do bispo, D. José empenhou-se no melhoramento do seminário episcopal da cidade de Belém, e foi responsável pela criação em 1848 do seminário em Barra do Rio Negro em Manaus, pondo a serviço da formação de sacerdotes sua qualificação intelectual, expectando preparar padres aptos a levar a menssagem cátolica aos locais mais ermos do extenso bispado do Pará, a fim de secundarizar o catolicismo popular tão comum na região.

\section{OS DESENCONTROS COM A MODERNIDADE.}

A Igreja Católica se depara com um mundo em constante tranformação aventado pela modernidade emergente, fruto da ascensão burguesa decorrente dos movimentos revolucionários nos séculos XVIII e XIX. Essas mudanças acarretavam incômodo ao conservadorismo católico, pois colocava em cheque sua condição de mediadora entre o céu e a terra. Em meio a esse cenário turbulento, a Cúria Romana reagiu tentando restaurar sua condição hegemônica mediante determinações visando perfilar a comunidade católica aos preceitos romanos, de tal modo que os perigos concernentes ao racionalismo moderno não atingisse o campo de força que a Igreja almejava criar em torno de seus fiéis.

Segundo Ivan Manoel (2004), essa dedicação à difusão do conservadorismo católico foi conduzida pelos papas Gregório XVI, Pio IX, Leão XIII, Pio X e Pio XI através da elaboração de encíclicas papais no intuito de direcionar o clero nos trilhos da reforma católica ultramontana, transparecendo um saudosismo medieval ao responsabilizar a modernidade pela crise de toda a estabilidade, paz, justiça e liberdade em benefício da "razão, no direito e na moral contratual, sem a tutela e a ingerência católica" (MANOEL,

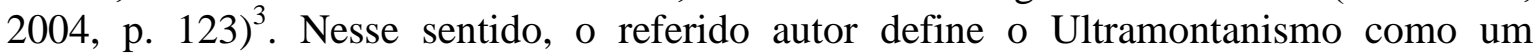
conjunto de medidas teórico e práticas alicerçadas na condenação a modernidade tendo a medievalidade como paradigma; centralização das atitudes da Igreja em Roma, reforçando a infalibidade papal, sobretudo após o estabelecimento dessa diretriz como dogma após o concilio do Vaticano I em 1870; valorização do episcopado e o reforço do magistério retomando o tomismo, considerado pela Igreja a única filosofia necessária para o cristão.

Para Jacques Le Goff $(2003)^{4}$, o conflito antigo/moderno, surgido no século XIX, se concentra e se radicaliza em torno de dois aspectos: o dogma e exegese bíblica; e a evolução social e política. Nessas circunstâncias, para a Igreja, o termo "moderno" passa a ser considerado pejorativo no século XIX na medida em que:

(...) os chefes da Igreja e os seus elementos tradicionalistas aplicam-no quer à teologia nascida da Revolução Francesa e dos movimentos progressistas da Europa do século XIX (o liberalismo e, depois, o 
socialismo) quer - o que, a seus olhos, é mais grave - aos católicos seduzidos por estas idéias ou apenas as combatam com tibieza. ${ }^{5}$

De acordo com Edgar Gomes (2009) ${ }^{6}$, as transformações na sociedade foram tão significativas que a euforia científica havia ganhado espaço onde antes imperava o teocentrismo, pois agora o antropocentrismo permitia ao homem caminhar sem necessitar da tutela da Igreja católica. Desse modo, se antes a ideia de mundo "real" - acessível por meio da transcendência dos corpos, espaço e tempo - e mundo ilusório se estabeleciam em planos diferentes; doravante a modernidade passa a posicionar ambos universos na terra, assim sendo, a sociedade moderna transformou em falso aquele universo referente ao passado histórico, enquanto que o universo verdadeiro seria o mundo físico e social. (BERMAN, 1986, p. 104) ${ }^{7}$. De maneira semelhante, Ivan Manoel (2004) ${ }^{8}$ afirma que os modernos pensadores leigos ao secularizarem a filosofia da história, condicionavam o trajeto histórico aos limites da temporalidade e retirava do conceito de progresso o sentido de transcendência, confiando em ser ele uma imanência do processo histórico.

Patricia Martins (2006) ${ }^{9}$ elucida que no Novo Testamento, sacerdócio e sacrifício constituem uma prática comum, em vista disso, os poderes de consagrar, oferecer e administrar os serviços simbólicos da religião cristã, tal como perdoar e absolver os pecados foram concedidos aos sacedotes - sucessores dos apóstolos - de acordo com as sagradas escrituras. Não sem razão, a reação da Igreja a essa ofensiva moderna devia começar pela formação clerical, pois o triunfo da doutrina cristã dependeria de soldados capacitados para combater os perigos que assombravam a instituição católica. Tendo a orientação tridentina como grande alicerce de sustentação, a campanha ${ }^{10}$ ultramontana dedicou atenção aos seminários episcopais, a fim de elevar o nivel moral e intelectual do clero.

Como a adolescência é normalmente inclinada a seguir os deleites mundanos caso não seja dirigida corretamente e não perseverando jamais na perfeita observância da disciplina eclesiástica sem um grandíssimo e essencialíssimo auxílio de Deus, a não ser que desde seus mais ternos anos e antes que os hábitos viciosos chequem a dominar toda a pessoa, seja lhes dada criação conforme a piedade e religião.

Estabelece o Santo Concílio que todas as catedrais metropolitanas e igrejas maiores que estas tenham a obrigação de manter e educar religiosamente e insistir na disciplina eclesiástica segundo as faculdades e extensão da diocese, certo número de jovens da mesma cidade e diocese, e se não houver nestas, então que sejam da mesma província, em um colégio situado perto das mesmas igrejas ou em outro lugar oportuno conforme ache o Bispo. ${ }^{11}$

Como se vê, o capítulo XVIII da assembleia tridentina chama atenção para os jovens que, sem o amparo dos centros de formação sacerdotal, podem ficar expostos aos riscos mundandos, assim, foi atribuído á figura prelado diocesano a incumbência relativa à administração dos seminários. Por conseguinte, tanto seminários quanto a autoridade do bispo foram defendidos nos escritos de Trento como elementos inerentes, pois, segundo Kenneth Serbin $(2008)^{12}$, a partir dos seminários, os bispos expectavam transformar os clérigos desviantes das sendas do catolicismo diocesano, em um corpo de sacerdotes obediantes aos principios religiosos, políticos e sociais da hierarquia católica. Isso porque a importância dos padres nessa reforma era tamanha que, tanto a identidade católica quanto o modelo da Igreja estavam fortemente vinculados à identidade do padre. Apesar da elabolaração de Serbin considerar a identidade do sacerdote para alavancar o 
Ultramontanismo, salientamos mais a importância da capacidade de comunicação e expressão das ferramentas da reforma católica ultramontana.

No Brasil esse afinco pela formação clerical foi disseminado por D. Antônio Ferreira Viçoso - bispo da diocese de Mariana - e outros bispos tendentes à cultura Utramontana. No que tange às ordens religiosas, os Padres da Congregação da Missão São Vicente de Paulo (conhecidos também como lazaristas) se destacaram ao transformar Minas Gerais em um polo disseminador do conservadorismo católico, ao passo que os discipulos lazaristas foram dando continuidade a essa empreitada, como por exemplo, D. João Antônio dos Santos ao inaugurar o seminário em Diamantina, D. Pedro Maria de Larceda que fundou um seminário no Rio de Janeiro, D. Luís Antonio dos Santos seminários em Fortaleza e Crato, e D. José Afonso de Moraes Torres, outro fruto da educação vicentina, que fundou em 1848 um seminário em Manaus. (SERBIN, 2008, p. 107-108)

Fora o interesse da Igreja católica, um quadro clerical eficaz também era pretendido pelo Estado, no entanto, cada uma das esferas de poder tinha seu desígnio. Além do interesse católico ja exposto, o governo imperial vislumbrava religiosos que atuassem no controle social, especialmente no campo, dessa maneira, a reforma clerical vicejou tanto conflitos quanto afinidades entre a construção do Estado brasileiro e o conservadorismo católico (SERBIN, 2008, p. 83). Até certo ponto, essa relação entre trono/altar exprimia benefício para ambos os lados, tendo em vista a asseveração de Fernando Neves (2009) ${ }^{13}$ quando assinala uma solidariedade ativa existente na relação Estado/Igreja, a partir do momento que a instituição religiosa usufruía dos recursos materiais advindos do Estado, assim como o Estado aproveitava a ramificação da Igreja que não deixava de ser representante do poder público - para estender sua autoridade a lugares onde o poder civil se fazia pouco presente. Todavia, os desgastes existentes entre Igreja e Estado potencializavam-se conforme aumentava o vínculo entre hierarquia católica brasileira e o pontífice romano, tornando a Igreja mais concentrada na empreitada católica romana do que na causa nacional. (FRAGOSO, 1992, p. 183)

\section{APLICAÇÃO DO ULTRAMONTANISMO NOS SEMINÁRIOS DA AMAZÔNIA.}

A Igreja no Brasil acompanhou as tendências transformadoras do mundo católico do século XIX influenciada pelas diretrizes romanas. Logo, essa busca por maior autonomia do poder espiritual frente ao poder civil provocou um estremecimento na relação de Padroado Régio ${ }^{14}$, embora o embate entre essas duas esferas só se configurasse mais incisivamente a partir da década de 1860 na Amazônia e no mundo. Entrementes, antes desse momento de turbulência, D. José Afonso de Moraes Torres ja se mostrava sintonizado aos ventos do Ultramontanismo, mesmo não expressando insatisfação escancarada quanto às intervenções do Estado nos negócios eclesiásticos. Mesmo assim, durante todo seu bispado, entre 1844 a 1857, D. José Torres se desdobrou em fazer da diocese do Pará um pasto espiritual substanciado pelos ensinamentos do conservadorismo católico, direcionando a população para o caminho da salvação, e secundarizando as práticas do catolicismo-luso brasileiro herdado desde os tempos coloniais.

Se mostrando afinado aos preceitos romanos, D. José Afonso Torres incorpora a aversão pelas ameaças modernas, conquanto, não esboce reação explícita contra a francomaçonaria, que décadas seguintes será combatida pela hierarquia católica. Mesmo assim, ele não fecha os olhos para os avanços modernos, já que, segundo Ivan Manoel (2004), na lógica da filosofia cristã católica da história, a valoração da vida religiosa deve ser elevada 
em detrimento da vida terrena, sendo a história da salvação a verdadeira história universal. Imerso no movimento de restauração da Igreja, D. José declara:

(...) e que outra cousa se pode diser a vista do triste quadro que nos apresentaõ os Christãos dos tempos modernos em suas vidas? Cada um fórma um sistema de Religião acommodado a seus caprichos, e torcendo todas as regras da sã moral do Evangelho, e desfigurando todo o sistema da Religião de Jesus Christo, inventa uma ao seo modo, e que de nenhuma maneira possa ir de encontro as suas más inclinações; de seos labios sahem sublimes apologias às virtudes Christãas, ao mesmo tempo que suas acções as desmentem; não se ataca directamente a Religião, mas se a despresa; uma incredulidade sem limites para todos os dogmas e misterios da fé, um gelado indiferentismo para todas as cousas santas, um profundo esquecimento dos proprios deveres christaõs, eis o caracter distinctivo do Seculo presente. ${ }^{15}$

Era a primeira vez que aquela diocese passava pela tentativa de reforma espiritual dessa grandeza, por isso, o bispo do Pará se valeu, em 1848, do jornal Synopsis Ecclesiastica como instrumentos de propagação da doutrina católica conservadora. Nesse periódico católico eram expostos "todos os escriptos que possão ser necessários para a publicação de huma Historia Ecclesiastica da Provincia, as leis que dizem respeito ao Clero, e a summa daquelas" "16. Redigido sob os auspícios do prelado diocesano, o jornal apresenta a seguinte definição sobre os seminários, que também pode ser considerada a visão de D. José Afonso:

Os seminários Ecclesiasticos, são santos retiros onde os jovens clérigos, e aquelles que aspirão às Santas Ordens vem a tempo moldar-se ao espirito de seu estado, e como nutrir-desd' a infancia do leite da doutrina Ecclesiastica e da Piedade Sacerdotal, que ahi se conserva como em sua fonte. ${ }^{17}$

Pouco mais de um ano após assumir a gestão da diocese, D. José tinha a intenção de se dedicar ás visitas pastorais, entretanto, devido ao estado de carência que vivia o seminário episcopal, ele teve que voltar sua atenção para esse centro de formação sacerdotal do Pará como consta no documento de 1845:

Este digno e virtuoso Prelado, a cujo cargo e direcção esta o Seminario, tem sido incansável no empenho de melhorar a instrucção, a que este pio Estabelecimento se propõe dar, empregando-se ele proprio com o veneravel Sacerdote, que lhe serve de Mestre de Cerimonias na regencia de alguma de suas Cadeiras com o mais desvelado zelo, e assiduidade. ${ }^{18}$

De acordo com João Santos $(1992)^{19}$ D. José Afonso executou ações renovadoras no seminário episcopal do Pará, buscando inspiração no Seminário de Caraça ${ }^{20}$, estabelecimento no qual ele havia sido formado pelos padres lazaristas; e que era referência no que tange a formação de religiosos portadores da cultura ultramontana. Levando em consideração esse antecedente, ele foi responsável pela vinda de seu antigo mestre em lógica - José Joaquim Alves - para auxiliar na formação dos seminaristas.

Logo que aqui cheguei, preparei-me para cumprir aquele meu desejo e obrigação; obstou-me porém o estado em que se achava o seminário episcopal, por quanto tive de dar-lhe novos estatutos, que procurei 
acomodar quanto pude ao do Seminário do Caraça, onde fui educado, e que tem dado grandes homens à Religião e ao Estado, onde ele figuram de uma maneira brilhante pelos seus talentos e virtudes; vi-me na necessidade de ir lecionar em uma das cadeiras de ensino com o Padre Mestre José Joaquim Mendes de Moura Alves, meu mestre de lógica naquele seminário, sacerdote de reconhecida ilustração (...). ${ }^{21}$

Segundo Riolando Azzi (1982) ${ }^{22}$, José Afonso de Moraes Torres foi formado em Caraça e depois de ordenado sacerdote em 1829, voltou ao estabelecimento para ocupar o cargo de professor de filosofia e retórica, sendo nomeado em 1834 como superior do Colégio de Congonhas do Campo (também gerido pelos lazaristas), ficando até 1838 quando se dirigiu para o Rio de Janeiro afim de assumir a função de pároco da freguesia do Engenho Velho. Paralelo à época em que José Afonso possuía vínculo estreito com os lazaristas na diocese de mariana, o Papa Gregório XVI, apegado às orientações tridentinas, dava início ao processo de difusão da fé católica por meio de seminários episcopais. (MARTINS, 2006, p. 48) Portanto, o futuro bispo do Pará acabou por vivenciar esse estimulo ao reforço do tradicionalismo católico, absorvendo essa preocupação com a formação sacerdotal e consequentemente com a organização dos seminários.

No contexto do século XIX também existiram seminários menores, que segundo Serbin $(2008)^{23}$, visavam o ensino acadêmico e religioso para crianças e adolescentes, evidenciando-se por ser um pré-requisitos para a entrada dos jovens nos seminários maiores. Seguindo essa premissa, D. José erigiu na cidade de Óbidos em 1846 o Colégio São Luiz Gonzaga:

E o nosso Exm. ${ }^{\circ}$ Prelado não podia por certo offerecer aos Jovens Obidenses mais insigne Protector no Collegio, que erigio. (...) Feliz Óbidos, que contas com os prontos meios de te levares a esse engrandecimento que só pode dar a instrucção quando formada nas solidas bazes de hua Religiosa educação, qual somente podem ministrar estes sagrados azilos da innocencia, especialmente destinados para nelles se formarem Ministros dignos do santuário. ${ }^{24}$

Como se vê, foi grande a gratidão tida por D. José pela sua dedicação ao Colégio de Óbidos, em razão do bispo ter marcado a região com um centro educacional de tendências católicas conservadoras, apontado como fundamental para o crescimento da localidade a partir da educação dos seus jovens à proporção que afastaria os meninos dos reflexos da modernidade emergente do século XIX. Por esse motivo, ao entender a importância de tal colégio, o prelado buscou alternativa de sustento do referido estabelecimento a partir das quantias oriundas da Irmandade de São Luiz Gonzaga.

$\mathrm{Na}$ tentativa de descentralizar a formação de religiosos na Amazônia, o prelado diocesano participa da criação, em 1848, do Seminário São José em Barra do Rio Negro (Manaus). Os passos dados pelo bispo estavam em sintonia com o que definia a assembleia tridentina: Naquelas que existirem dioceses dilatadas, possa ter o Bispo um ou mais colégios, segundo the parecer mais conveniente, os quais deverão depender em tudo do colégio que tenham fundado e estabelecido na cidade episcopal ${ }^{25}$. Justamente por conseguir fundar uma casa de educação sacerdotal longe da capital da diocese, D. José Torres expressa satisfação por meio de discurso:

As casas de educação forão em todos os tempos consideradas, como outros tantos asilos em que se salva da ignorância, e immortalidade a mocidade, que sem estes recursos deixa sepultados muitas vezes índoles, 
e talentos, que se podião aproveitar, e de grandes esperanças para a Religião e para o Estado: são ellas a fonte de que dimanão torrentes de mil bens á Sociedade e donde tem sahido esses raros homens, que a engrandecem nos differentes ramos de que a mesma se compõem: se o homem tudo deve a sua primaria educação, e se á esta, quando dada nos Colllegios estão ligados bens, que se não podem esperar de Jovens educados no meio do contagio do seculo, expostos a todos os perigos d'um mundo corrupto, quem pode deixar de considerar os Collegios como os unicos meios talvez de remir da corrupção geral a inexperiente mocidade, e appreciar o apparecimento destes estabelecimentos? E que vantagens não tira a Comarca com esta creação? As sciencias, as luzes aqui recebidas hirão em breve tempo deste foco de illustração aos differentes pontos della, ramificando-se dest'arte a instrucção; porque Senhores, os Seminaristas serão outros tantos mestres espalhados em differentes pontos, que hirão communicar os conhecimentos aqui obtidos á seos patricios, convidados ou pelo interesse, ou pelo zelo patriotico de ver aproveitada a mocidade $(\ldots)^{26}$

O bispo ressalta as benesses que proporcionaria para a Igreja e Estado o surgimento do seminário no Rio Negro, estendendo essa benfeitoria para a sociedade como um todo, ao ganhar cada vez mais vocacionados da batina imbuídos na reprodução dos valores católicos. Isso mostra o grau de valorização que o prelado diocesano atribuía a formação de padres, pois não só os jovens estão sendo afastados do contágio do século expressão da mentalidade antiliberal da Igreja Católica -, mas também esses futuros ministros de Deus, plasmados nos ensinamentos pontifícios, trabalhariam no sentido de orientar os fiéis na doutrina católica, reforçando as orientações tridentinas para as terras amazônicas.

Outrossim, é possível depreender como o bispo aliava as faculdade racionais a fé católica, conferindo ao recém criado Seminário São José o papel de centro irradiador dessas manifestações. Dessa forma, a carga intelectual do bispo, acumulada desde os tempos de Caraça, lhe permitiu publicar em 1852, o "Compendio De Philosophia Racional" no intuito de orientar da forma mais adequada os candidatos ao sacerdócio dentro do seminário, ofertando uma visão de mundo dotada de forte caráter doutrinário, moral e religioso. Compreende também uma tentativa de aclarar as inteligências daquele tempo a se dedicarem a correta interpretação sobre os usos da razão:

A rasão por si mesma não leva ninguem ao erro; por quanto a rasão é a faculdade de perceber distinctamente o nexo das verdades, ora quem assim percebe a ligação que há entre as verdades, tira legitimas illações de princípios verdadeiros, não pode por conseguinte errar: todo o erro por tanto nasce não do uso da rasão, mas de seo abuso, e por isso, quando dividimos a rasão em recta, e não recta, só queremos com isto significar que se dá abuso da rasão(...) ${ }^{27}$

Vale lembrar que a razão foi designada pelo liberalismo como instrumento de reflexão sobre a condição de submissão absorvida pela sociedade ante o Estado e Igreja. Diante dessa ambiência, Ivan Manoel $(2004)^{28}$ defende a presença, nas publicações de Gregório XVI, e de forma mais contundente nos escritos de Pio $\mathrm{IX}^{29}$, a tendência do mundo católico à rejeição ao conjunto teórico e filosófico da modernidade, pois o verdadeiro saber seria aquele que orientaria ao entendimento da doutrina cristã, e consequentemente ao conhecimento de Deus. No entanto, em seu livro, o bispo não 
condenava indiscutivelmente a faculdade da razão, desde que ela fosse usada de forma adequada aos olhos da Igreja. Influenciado pelo tomismo, D. José entendia a filosofia como um dos meios de melhor conhecer os fundamentos da fé, e utilizando-a como arma contra os ataques da impiedade, do cisma, e da heresia, ela seria bastante proveitosa.

Importante perceber que na diocese de São Paulo, sob a direção de D. Antônio Joaquim de Melo ${ }^{30}$, publicações como o Manual de Teologia Dogmática, elaborado pelo Abade Gousset em 1852 e o Compêndio de Filosofia Católico Racional, escrito por Firmino de Centellhas (vice-reitor e professor do seminário), integraram os manuais de formação no seminário porquanto pregavam aversão ao racionalismo moderno devido a esta concepção descartar a razão fundamentada na fé, sinalizando uma maior atenção na formação dos vocacionados da batina no que diz respeito às bases filosóficas pautadas na escolástica de São Tomás de Aquino. (MARTINS, 2009, p.10) José Arruda Campos $(1998)^{31}$ destaca, junto a outros nomes, D. José Afonso Torres como contribuinte para essa produção filosófica, pois é patente a inspiração tomista na obra do bispo diocesano ao condicionar a razão ao conhecimento divino, não por acaso, já que, segundo Serbin $(2008)^{32}$ filosofia e teologia eram as duas matérias mais importantes na formação sacerdotal.

\section{CONTORNANDO AS DIFICULDADES MATERIAIS DOS SEMINÁRIOS.}

Segundo Riolando Azzi (1983) ${ }^{33}$, durante muito tempo no Brasil a formação do clero foi conduzida pelos religiosos da Companhia de Jesus, sendo datado apenas no século XVIII o surgimento dos seminários episcopais propriamente ditos. Porém, foi no contexto do século XIX que os bispos foram substituindo a aleatória formação sacerdotal, pelo seminário tridentino, que reforçava a ortodoxia católica (SERBIN, 2008, p. 78).

Visando promover essa transformação na formação clerical da Amazônia, D. José Afonso Torres busca melhorar as condições do precário seminário episcopal de Belém, agravadas pelos desgastes resultantes da revolução cabana que havia deixado à diocese devastada.

O edifício está summamente arruinado em consequencia das ballas que nelle forão empregadas no tempo da rebelião, e necessita ser reconstruído. Os seus rendimentos são muito diminutos, e sofre, quanto á prestação que lhe deve ser feita pelos Cofres Pronvinciaes, o mesmo atrazo que os outros Estabelecimentos e Empregados. ${ }^{34}$

Herança dos jesuítas, o seminário episcopal de Belém, existente desde 1751, carecia de condições apropriadas para o desempenho do ensino aos seminaristas. Contribuía para essa precariedade da formação de clérigos, o envolvimento do governo imperial - pouco comprometido com a causa ultramontana -, pois dele dependeria o fornecimento de recursos materias para suprir esses centros de formação (FRAGOSO, 1992, p.196). Dessa maneira, o sustento da estrutura física dos seminários; dos seminaristas pobres; decretos em favor da criação de novas cadeiras para o ensino nos seminários; bem como o pagamento de professores era de competência do poder civil, no entanto, esse axulio do Estado estava inserido na lógica regalista que esbarrava no conservadorismo da hierarquia católica.

Com isso, o seminário de Belém tinha como principal fonte de sustento os recursos advindos do governo provincial, contudo, a situação era tão adversa que as despesas da casa de formação eram maiores que a receita ${ }^{35}$. Ainda assim, a despeito da 
debilidade pelo qual passava o seminário episcopal de Belém nos anos de 1840, a gestão espiritual do D. José parece propocionar melhorias à formação de novos padres, uma vez que mesmo poucos anos a frente da diocese do Pará, houve aumento gradual do número de seminaristas no estabelecimento, rendendo ao bispo elogios pela tenacidade no ensino, mesmo em condições desfavoráveis.

Consola em verdade ver o estado florescente das Aulas do Seminario do Pará a despeito de quasi insuperaveis obstaculos, com que luta este Estabelecimento na deficiencia de meios para recompensar seus Empregados. Graças ao Sabio e Virtuoso Prelado, que na perfeição desta Obra tem posto o seu maior disvello, e cuidado. ${ }^{36}$

O auxílio do Estado era indispensável e se fazia naturalizado no projeto ultramontano do bispo. Por isso, essa solidariedade ativa contagiava mesmo quem militava nas fileiras do Estado, tal como ocorreu com Euzébio de Queiroz, Ministro e Secretario de Estado dos Negócios da Justiça, ao comtemplar com recursos públicos - por meio de decreto de 1851 - os seminários da Bahia, Minas Gerais e Pará. Por este motivo, D. José Afonso Torres expressou sua gratidão por quem ali estava propugnando medidas convenientes ao bom andamento do pastoreio espiritual durante um século carregado de valores oriundos da modernidade.

Começou porém em 1851 do seculo XIX a declinar a seu accaso e felizmente tambem as ideias declinaram da marcha até entaõ seguida; um homem appareceu nessa epocha no gabinete imperial, que conhecendo toda importância do clero, persuadiu a nosso adorado monarcha de que já era tempo de levanta-lo do batimento em que jazia, e de attender seus repetidos reclamos, e com o memoravel decreto de 11 de outubro de 1851 deu começo a obra, creando nos seminarios episcopaes novas cadeiras de ensino eclesiastico: esse homem é o Exm. ${ }^{\circ} \mathrm{Snr}$. Conselheiro Euzebio de Queiroz Coutinho Mattoso Camara, a quem coube a gloria de incetar a empreza do melhoramento do clero brasileiro: estou persuadido de que o actual gabinete, que nutre estas mesmas ideias deste estadista, à levará a perfeiçaõ a que deve chegar, e tenho disto uma prova; a maioria dos representantes da naçaõ que é a expressaõ viva de seus sentimentos, acaba neste anno de orçar quantias para o melhoramento material dos seminarios, creaçaõ de duas faculdades theologicas, e augmentos da congrua dos bispos ${ }^{37}$

O decreto supracitado causou grande entusiasmo ao bispo, pois proporcionava expectativas de melhores horizontes à formação sacerdotal na medida em que aumentava $o$ numero de disciplinas ensinadas nos seminários. Entre essas novas cadeiras de ensino estabelecidas, estava a cadeira de "Língua Indígena Geral", cujo conhecimento he indispensável não só para a Missão e Catechese dos Indios, como por exercer o Ministério Sacerdotal em alguns pontos do Império. ${ }^{38}$

No prefácio do "Compendio de Lingua Brazilica" - escrito pelo coronel reformado do exercito Raymundo Correia de Faria que fora nomeado por D. José Torres como sucessor de Manoel Justiniano de Seixas ao posto de lente da respectiva cadeira no Seminário - fica expresso a contribuição do bispo para essa conquista da Igreja, além de sua preocupação com a catequização dos nativos: 
Commovido o nosso exímio Prelado da necessidade que havia, de chamar ao gremio da Igreja essas hordas de selvagens, barbaras, ignorantes, embratecidas, extraviadas, e sobre tudo dignas de compaixão; espalhadas pelas nossas vastas e incultas florestas, sem conhecimento algum de Deos nem de nossas crenças; e sendo o meio mais apropriado o antigo methodo das Missões, julgou indispensavel, principalmente para aquelles candidatos que se propozerem ás Freguesias do interior, o conhecimento da Língua Geral, adoptada pelos Jesuitas, e por meio da qual tudo havião conseguido n'aquelles tempos. ${ }^{39}$

O bispo da diocese do Pará se destacou como pioneiro no que tange a formação sacerdotal, alinhado a hierarquia romana, e adaptando esse projeto a realidade local, visto que, os indígenas não poderiam ficar de fora dos planos referentes à formação do clero. Além disso, a dificuldade ganhava maior proporção ao pensar o bispado do Pará compreendendo toda a atual Amazônia, abrangendo uma área de $4.000 .000 \mathrm{Km}^{2}$ e tendo como sede a cidade de Belém, o que dificultava sobremaneira a gestão espiritual de quem almeja formar clérigos comprometidos com o modelo do catolicismo diocesano.

\section{CONSIDERAÇÕES FINAIS}

Tendo em vista os riscos para a Igreja, é possivel perceber o descontentamento de D. José Afonso de Moraes Torres relacionado à influência que a modernidade aprensentava à hegemonia da Igreja católica na região Amazônica. Entretanto, essa preocupação não fica apenas no discurso, já que o bispo do Pará se desdobra diante das várias dificuldades encontradas para desempenhar seu oficio pastoral, identificando na educação sacerdotal um meio pelo qual o catolicismo reproduziria os principios de sua religião, sem desconsiderar, de certa forma, a lógica do Padroado Régio e a realidade local.

Portanto, o trabalho buscou possibilidades de levantar novas discussões e reflexões sobre os primórdios do Ultramontanismo na Amazônia, enfatizando as medidas de um bispo que não vivencia um clima de abalo vultoso na aliança Trono/altar, mas que, para dar prosseguimento ao seu múnus pastoral, se empenha na formação de novos padres.

Ainda que a documentação pesquisada forneça poucas informações sobre o funcionamento cotidiano dos seminários, e consequentemente da eficácia na formação sacerdotal colocada em prática por D. José Torres, é certo que pelo menos quantitativamente, esse projeto surtiu efeito, visto que, ao final de seu bispado, foram sagrados 89 padres enquanto que no bispado de seu sucessor, D. Macedo Costa- grande expoente do Ultramontanismo no século XIX na Amazônia -, foram apenas 29 as sagrações ${ }^{40}$. Essa obstinação de D. José Afonso Torres lhe rendeu elogios disferidos por D. Macedo:

Fundou dois estabelecimentos pios de educação, e instrucção religiosas, o colégio de Obidos, destinado para meninos pobres desvalidos, e os seminarios de S. José na capital do Amasonas, o primeiro inaugurado em Desembro de 1846, e o segundo em 14 de Maio de 1848. Seu zêlo, porém, mal compreendido por aquelles, que com elle se encommodavam, lhe acarretou amargos desgostos, que muito influiram no seu animo, para que resignasse o bispado no anno de 1857, e se retirasse para a côrte do Rio de Janeiro, deixando a Diocese no dia 19 de Julho do mesmo anno. ${ }^{41}$ 
Apesar da declaração de D. Macedo Costa ter sido feita em meio a uma homenagem fúnebre ao recém-falecido D. José Afonso Torres, é possível perceber o quão importante o antigo prelado diocesano tinha sido à propagação do catolicismo diocesano no Pará ao empenhar-se na revitalização do seminário de Belém, além da fundação de outras casas de educação na Amazônia, mesmo enfrentando resistência de setores da sociedade, tanto católicos quanto leigos, somando a outros desgastes que culminaram na renúncia do bispo.

Em termos comparativos, D. Macedo Costa fica atrás de D. José no que tange à fundação de casas de educação sacerdotal. No século XIX não eram numerosos os seminários no Brasil imperial, todavia, a diocese do Pará era contemplada com a presença dois seminários episcopais - sem falar dos colégios católicos - graças à diligência do exlazarista D. José Afonso e sua inspiração nas prédicas ultramontanas fundamentadas no Concílio de Trento, secundarizando o catolicismo devocional e colocando seu conhecimento a disposição do aprendizado dos vocacionados da batina.

\section{REFERÊNCIAS}

ANDRADE, Allan.; NEVES, F. A. F. . A romanização no Pará: D. Afonso Torres e as atribulações de governar espiritual e materialmente a diocese. Revista Eletrônica Documento/Monumento, v. 10, p. 12-23, 2013.

AZZI, Riolando. A Instituição Eclesiástica durante a Primeira Época Colonial. In: Hoornaert, Eduardo. História da Igreja no Brasil. TOMO II,1. Petrópolis: Vozes, 1983.

AZZI, Riolando. D. José Afonso de Moraes Torres, ex- lazarista no bispado do Pará. In: Revista Convergência. n. 151. Rio de Janeiro, 1982.

BERMAN, Marshall. Tudo que é sólido desmancha no ar: a aventura da modernidade. São Paulo: Companhia das letras, 1986, pp. 85-125.

CAMPOS, Fernando Arruda. Tomismo no Brasil. São Paulo: Paulus, 1998.

CARVALHO, José Murilo de Carvalho. A construção da ordem: a elite política imperial; Teatro de sombras: a política imperial. $2^{\mathrm{a}}$ ed. Rio de Janeiro: Editora UFRJ, RelumeDumará, 1996.

COSTA, Emília Viotti Da. Liberalismo: Teoria e prática. In: Da Monarquia à República: momentos decisivos. São Paulo: Editora UNESP, 1998.

FARIA, F.R.C. de. Compendio da Lingua Brazilica. Pará, Typ. de Santos \& Filho, 1858.

FRAGOSO, Hugo. A igreja na formação do estado liberal (1840-1875). In: História da Igreja no Brasil: Ensaio de interpretação a partir de um povo - segunda época. Tomo II/2. HOORNAERT, Eduardo (org.). Petrópolis, RJ: Ed. Vozes, 1992.

GOMES, E. S. A Dança Dos Poderes: Uma História Da Separação Estado-Igreja No Brasil. 1. ed. São Paulo: D'escrever, 2009. v. 1. 236p.

HOORNAERT, Eduardo. A Cristandade durante a Primeira Época Colonial. In: Hoornaert, Eduardo et al. História da Igreja no Brasil. Tomo II, v. 4. Petrópolis, Vozes, 1992.

JÚNIOR, Donato Mello. Dom José Afonso de Morais Torres. Nono Bispo do Pará (18441859). Revista do instituto histórico e geográfico do Brasil. v. 328, p. 5-22, 1980. 
LE GOFF, Jacques. História e Memória. Tradução de Irene Ferreira, Bernardo Leitão e Suzana Ferreira Borges. 5 ed. Campinas: Unicamp, 2003.

LYNCH, John. A Igreja católica na América Latina, 1830 - 1930. In: História da América Latina. Vol. IV. BETHELL, Leslie (org.). São Paulo: Editora da Universidade de São Paulo, 2001.

MANOEL, Ivan Aparecido. O pêndulo da História. Tempo e eternidade no pensamento Católico (1800-1960). Maringá: Eduem, 2004.

MARIZ, Cecília. Instituições tradicionais e movimentos emergentes. In: Frank Usarski; João Décio Passos. (Org.). Compêndio de Ciência da Religião. 1ed. São Paulo: Paulinas/ Paulus, 2013, v. , p. 301-312.

MARTINS, Patrícia Carla de Melo. Conservadorismo, educação e tomismo no império brasileiro. Revista Brasileira de História das Religiões, v. 3, p. 239-257, 2009.

MARTINS, Patrícia Carla de Melo. Seminário Episcopal de São Paulo e o paradigma conservador do século XIX. 2006. 309 f. Tese (Doutorado em Ciência da Religião). Pontifícia Universidade Católica de São Paulo, São Paulo. 2006.

NEVES, F. A. F. Solidariedade e conflito: Estado liberal e nação católica no Pará sob o pastorado de Dom Macedo Costa (1862-1889). Doutorado em História, Pontifícia Universidade Católica de São Paulo, PUC/SP, Brasil, 2009.

SANTOS, João. A romanização da igreja católica na Amazônia (1840-1880). In: História da Igreja na Amazônia. HOORNAERT, Eduardo (org.). Petrópolis, RJ: Ed. Vozes, 1992.

SERBIN, Kenneth P. Motta, Laura Teixeira. Padres, celibato e conflito social: uma história da Igreja Católica no Brasil. São Paulo: Companhia das Letras, 2008.

SOUZA, Françoise Jean de Oliveira. Do Altar a Tribuna. Os padres na formação do Estado Nacional brasileiro (1823-1841). (Tese de Doutorado). Rio de Janeiro: UERJ, 2010.

TORRES, Afonso de Moraes. Collecção de Algumas circulares e portarias mais importantes de S. Ex. ${ }^{a}$ Reverendissima o Senhr. Bispo do Pará. Typ. de Santos \& Filho. 1856.

\footnotetext{
${ }^{1}$ Mestrando em História, Universidade Federal do Pará, Instituto de Filosofia e Ciências Humanas. allan.andrade89@hotmail.com

${ }^{2}$ Doutor em História Social pela PUC-SP. Prof. Dr. Faculdade de História da Universidade federal do Pará, Instituto de Filosofia e Ciências Humanas. Email: fafn@ufpa.br

${ }^{3}$ MANOEL, Ivan Aparecido. O pêndulo da História. Tempo e eternidade no pensamento Católico (18001960). Maringá: Eduem, 2004. p. 44.

${ }^{4}$ LE GOFF, Jacques. História e Memória. Tradução de Irene Ferreira, Bernardo Leitão e Suzana Ferreira Borges. 5 ed. Campinas: Unicamp, 2003.

${ }^{5}$ Ibidem. p. 186.

${ }^{6}$ GOMES, E. S. A Dança Dos Poderes: Uma História Da Separação Estado-Igreja No Brasil. 1. ed. São Paulo: D'escrever, 2009. v. 1. p. 11-12.

7 BERMAN, Marshall. Tudo que é sólido desmancha no ar: a aventura da modernidade. São Paulo: Companhia das letras, 1986, pp. 85-125.
} 


\footnotetext{
${ }^{8}$ Ibidem. p. 42.

${ }^{9}$ MARTINS, Patrícia Carla de Melo. Seminário Episcopal de São Paulo e o paradigma conservador do século XIX. 2006. 309 f. Tese (Doutorado em Ciência da Religião). Pontifícia Universidade Católica de São Paulo, São Paulo. 2006. p. 47.

10 "Campanha" aqui está empregada dentro do conceito de Cecilia Mariz, como sendo um projeto de mudança religiosa ou cultural-religiosa liderado pelas lideranças da instituição, que no caso da Igreja Católica poderia ser o Papa, ou mesmo os bispos. Ver: MARIZ, Cecília. Instituições tradicionais e movimentos emergentes. In: Frank Usarski; João Décio Passos. (Org.). Compêndio de Ciência da Religião. 1ed. São Paulo: Paulinas/ Paulus, 2013, v. , p. 301-312.
}

11 Concílio de Trento. Sessão XXIII. Capitulo XVIII. Disponível em: <http://agnusdei.50webs.com/trento28.htm>. Acesso em: 08 Fev. 2015.

12 SERBIN, Kenneth P. Motta, Laura Teixeira. Padres, celibato e conflito social: uma história da Igreja Católica no Brasil. São Paulo: Companhia das Letras, 2008. p. 29.

${ }^{13}$ NEVES, F. A. F. Solidariedade e conflito: Estado liberal e nação católica no Pará sob o pastorado de Dom Macedo Costa (1862-1889). Doutorado em História, Pontifícia Universidade Católica de São Paulo, PUC/SP, Brasil, 2009. p. 07.

${ }^{14}$ Aliança entre poder temporal e espiritual que garantia a Igreja católica o monopólio da propagação da fé. No Brasil, apesar da constituição de 1824 permitir a existência de outras religiões que não fosse a católica, acabava limitando ao culto doméstico a expressão dessas outras formas religiosas, como se vê no Art. $5^{\circ}:$ " $A$ Religião Católica Apostólica Romana continuará a ser a religião do Império. Todas as outras religiões serão permitidas com seu culto doméstico, ou particular, em casas para isso destinadas, sem forma alguma exterior de templo".

${ }^{15}$ TORRES, José Afonso de Morais. PASTORAL. Treze de Maio, Belém, 22 Maio 1852. p.1.

${ }^{16}$ ANNUNCIOS. Treze de Maio, Belém, 23 Ago. 1848.

${ }^{17}$ SEMINARIOS ECCLESIASTICOS. Synopsis Ecclesiastica, Belém, 20 Nov 1848. p. 62.

${ }^{18}$ Discurso recitado pelo exm.o sñr doutor João Maria de Moraes, vice-prezidente da provincia do Pará na abertura da segunda sessão da quarta legislatura da Assembléa Provincial no dia 15 de agosto de 1845. Pará, Typ. de Santos \& filhos, 1845. p. 15. Disponível em: 〈http://brazil.crl.edu/bsd/bsd/504/000015.html>. Acesso em: 26 Jan 2015.

${ }^{19}$ SANTOS, João. A romanização da igreja católica na Amazônia (1840-1880). In: [HOORNAERT, Eduardo (org.)] História da Igreja na Amazônia. Petrópolis, RJ: Ed. Vozes, 1992. p. 299.

${ }^{20}$ Caraça é considerado o reduto do conservadorismo católico, onde os padres lazaristas contribuíram significativamente para a introdução o Ultramontanismo no Brasil.

${ }^{21}$ Itinerário das visitas do Exmo. e Revmo, Sr. D, José Afonso de Moraes Torres, bispo da diocese do Grão Pará, Pará, 1852, pp. 3-4.

${ }^{22}$ Ibidem. p. 177.

${ }^{23}$ Ibidem. p. 109

${ }^{24}$ BASTOS. Luiz Barroso de. Treze de Maio, Belém, 6 Set 1851. p.7.

25 Concílio de Trento. Sessão XXIII. Capitulo XVIII. Disponível em: <http://agnusdei.50webs.com/trento28.htm>. Acesso em: 08 Fev. 2015.

26 TORRES, José Afonso de Moraes. Treze de Maio, Belém, 19 ago. 1848. Disponível em: <http://memoria.bn.br/DocReader/docreader.aspx?bib=700002\&pasta=ano\%20184\&pesq=CREA\%C3\%87\% C3\%830\%20DE\%20UM\%20SEMINARIO\%20ESPISCOPAL>. Acesso em: 14 de Abril 2013.

${ }^{27}$ TORRES, Afonso de Moraes. Compêndios de Philosophia Racional. 1952.p. 55.

${ }^{28}$ MANOEL, Ivan Aparecido. O pêndulo da História. Tempo e eternidade no pensamento Católico (18001960). Maringá: Eduem, 2004. p. 45-51.

${ }^{29}$ Promulgado por Pio IX em 1864, o Syllabus condenava 80 erros que contrariavam a doutrina católica na época, entre eles o papa condenava a seguinte visão sobre a razão: "A razão humana, considerada sem 
relação alguma a Deus, é o único árbitro do verdadeiro e do falso, do bem e do mal, é a sua própria lei e suficiente, nelas suas forças naturais, para alcançar o bem dos homens e dos povos."

${ }^{30} \mathrm{O}$ bispo Antônio Joaquim de Melo se destacou ao buscar implantar as diretrizes ultramontanas na diocese de São Paula na qual esteve a frente entre 1852 a 1861.

${ }^{31}$ CAMPOS, Fernando Arruda. Tomismo no Brasil. São Paulo: Paulus, 1998. p. 45-52.

${ }^{32}$ Ibidem. p. 106

33 AZZI, Riolando. A Instituição Eclesiástica durante a Primeira Época Colonial. In: Hoornaert, Eduardo. História da Igreja no Brasil. TOMO II,1. Petrópolis: Vozes, 1983.

${ }^{34}$ Discurso recitado pelo exm.o snr. desembargador Manoel Paranhos da Silva Vellozo, presidente da provincia do Pará, na abertura da primeira sessão da quarta legislatura da Assembléa Provincial no dia 15 de agosto de 1844. Pará, Typ. de Santos \& menores, 1844. Disponível em: $<$ http://brazil.crl.edu/bsd/bsd/503/000057.html >. Acesso em: 18 Outubro 2013.

${ }^{35}$ Os problemas referentes ao custeio dos seminários ficam expressos nesse trecho: A Receita do Seminário no anno findo foi de 6:193\$000 réis, e a sua Despeza de 6:741\$404 réis, ficando por pagar a seus professores $950 \$ 000$ réis de ordenados vencidos pelo atraso da pensão, que lhe presta o Thesouro Provincial, e que monta em divina a mais de um conto de réis. Discurso recitado pelo exm.o sñr doutor João Maria de Moraes, vice-prezidente da província do Pará na abertura da segunda sessão da quarta legislatura da Assembleia Provincial no dia 15 de agosto de 1845. Pará, Typ. de Santos \& filhos, 1845. Disponível em: < http://brazil.crl.edu/bsd/bsd/504/000015.html>. Acesso em: 20 Setembro 2014.

36 SEMINÁRIO DO PARÁ. Treze de Maio, Belém, 22 Ago. 1846. Disponível em: $<$ http://memoria.bn.br/DocReader/docreader.aspx?bib=700002\&pasta=ano $\% 20185 \& p e s q=j o s e \% 20 \mathrm{bispo}$. Acesso em: 19 Setembro 2013.

37 TORRES, José Afonso de Moraes. Estrella do Amazonas, Manaós, 4 fev. 1854. Disponível em:<http://memoria.bn.br/DocReader/docreader.aspx?bib=213420\&pasta=ano\%20185\&pesq=prelado\%20di ocesano>. Acesso em: 26 de Maio 2013.

${ }^{38}$ 1852, p. 29: < http://brazil.crl.edu/bsd/bsd/u1843/000029.html >.

${ }^{39}$ FARIA, F.R.C. de. Compendio da Lingua Brazilica. Pará, Typ. de Santos \& Filho, 1858.

${ }^{40}$ Arquidiocese de Belém - 250 anos do bispado, Belém- Pará, 1969.

41 COSTA, Antonio de Macedo. Estrella do Amazonas, Manaós, 4 fev. 1854. Disponível em: $<$ http://memoria.bn.br/DocReader/docreader.aspx?bib=213420\&pasta=ano\%20185\&pesq=prelado\%20di ocesano>. Acesso em: 26 de Maio 2013. Jornal estrela do norte, fala de D. Macedo Costa

Recebido: $\quad$ abr/15 $\quad$ Aprovado: jun/15 